\title{
A comment on framing effects in linear public good games
}

\author{
Edward Cartwright ${ }^{1}$
}

Received: 19 May 2015/Revised: 24 March 2016/Accepted: 30 March 2016/

Published online: 9 April 2016

(C) Economic Science Association 2016

\begin{abstract}
A number of recent papers have looked at framing effects in linear public good games. In this comment, I argue that, within this literature, the distinction between give-take and positive-negative framing effects has become blurred, and that this is a barrier towards understanding the experimental evidence on framing effects. To make these points, I first illustrate that frames can differ along both an externality and choice dimension. I then argue that the existing evidence is consistent with a strong positive-negative framing effect but no givetake framing effect on average contributions.
\end{abstract}

Keywords Framing $\cdot$ Public good $\cdot$ Give $\cdot$ Take $\cdot$ Cooperation

JEL Classification $\mathrm{H} 41 \cdot \mathrm{C} 92 \cdot \mathrm{C} 72$

\section{Introduction}

There is extensive evidence of framing effects in linear public good games (e.g. Andreoni 1995; Cookson 2000; Park 2000; Dufwenberg et al. 2011; Khadjavi and Lange 2015; Cox 2015). In short, it appears that payoff irrelevant differences in the way a public good game is presented to experimental subjects can systematically influence the amount contributed towards the public good. This is a fascinating finding that, amongst other things, provides a valuable way to discern the reasons

Electronic supplementary material The online version of this article (doi:10.1007/s40881-016-0024-8) contains supplementary material, which is available to authorized users.

Edward Cartwright

E.J.Cartwright@kent.ac.uk

1 School of Economics, University of Kent, Canterbury, UK 
why people contribute (or do not) towards public goods (see e.g. Ellingsen et al. 2012; Fosgaard et al. 2014, 2015; Gächter et al. 2014). To draw correct inferences about framing effects it is, however, clearly crucial to carefully distinguish between the different frames considered. This paper is motivated by a concern that this is not being done.

I particularly want to emphasize the difference between a positive-negative framing effect and give-take framing effect. Positive-negative framing (more details will follow) reflects whether the positive externality of contributing to the public good or the negative externality of not contributing are emphasized. Andreoni (1995), along with the follow up studies of Park (2000) and Fujimoto and Park (2010), study a positive-negative framing effect. Give-take framing, by contrast, reflects the choice a person has to make (and their initial allocation). Specifically, whether they are asked to contribute to a public good or take from a public resource. Most recent studies, e.g. Cubitt et al. (2011a), Dufwenberg et al. (2011), Fosgaard et al. (2014), Khadjavi and Lange (2015) and Cox (2015), focus on a give-take framing effect.

We shall see that it is possible to have a positive-give, negative-give, positivetake and negative-take frame. The positive-negative framing effect should, therefore, be seen as distinct from the give-take framing effect. This distinction has, though, become blurred within the literature. Indeed, anyone reading the recent literature would surely come away with the impression that Andreoni (1995) considered a give-take framing effect. ${ }^{1} \mathrm{He}$ did not. Interestingly, Andreoni (1995, p. 12) anticipated such confusion: 'other psychological experiments that I am aware of are not strictly comparable to the one reported here. One reason is that they did not present neutral environments. In particular, these experiments instructed subjects to "give some" in positive frames and to "take some" in negative frames, which could influence outcomes'.

Somewhere along the line the true insight of Andreoni (1995) seems to have been lost. But, this is about more than historical accuracy. Picking apart the distinction between the positive-negative and give-take framing effects seems necessary to appropriately interpret the findings of recent experimental studies. We shall see that there is clear and unambiguous evidence of a positive-negative framing effect (e.g. Andreoni 1995; Park 2000). At face value, the evidence for a give-take framing effect appears far more mixed, with some studies showing contributions are higher in the give frame and some in the take frame (Gächter et al. 2014; Cox and Stoddard 2015). I want to argue here that these mixed results stem from a failure to control for the positive-negative effect. In particular we need to question whether studies are

\footnotetext{
1 To give a selection of quotes: Khadjavi and Lange (2015) write 'We replicate Andreoni (1995)'s finding that agents behave more selfishly when taking from a public account that when giving to a public good'. Cubitt et al. (2011a, p. 255) write 'The framing manipulation we consider... has a Give versus Take form, previously studied in social psychology and similar to that introduced in economics by Andreoni (1995).' Dufwenberg et al. (2011, p. 462) write 'A common result is that in the GIVE treatment contributions to a repeatedly played pubic good game are higher than in the TAKE treatment (cf.... Andreoni 1995;... Park 2000)'. Finally, Fosgaard et al. (2014, p. 134) write 'framing the cooperative decision as taking from a public good vs. giving to a public good (Andreoni 1995)'. Footnote 5 of Gächter et al. (2014) is a rare recognition of the differences between Andreoni (1995) and recent studies like Dufwenberg et al. (2011).
} 
comparing a positive-give frame with a negative-take frame (where the positivenegative effect will be present) or with a positive-take frame (where it will not). Once we do this the evidence for give-take framing becomes more consistent. Indeed, we shall see that there is little evidence of a give-take framing effect on contributions in linear public good games. Note, however, that there is evidence of a give-take framing effect on beliefs and cooperation attitudes.

To make these points clear I will distinguish three dimensions along which the frames used in linear public good game experiments differ. These will be called the (1) externality, (2) choice, and (3) initial allocation dimensions. The easiest way to illustrate the relevant distinctions is through examples, and so that is the approach I will take. I begin, in Sect. 2, by reviewing the positive-negative externality distinction made by Andreoni (1995). With this done we can then, in Sect. 3, better understand the give-take choice distinction commonly studied in the literature. Given that I am being critical of the language used in some of the literature, let me emphasize that my objective here is not to question in any way the importance of this work. Indeed, it is the very importance of the experiments that motivates the need for a careful distinction between framing effects. My goal, therefore, is one of constructive criticism. I return to this point in Sect. 4 with a concluding discussion.

\section{A positive-negative framing effect}

As already previewed I will begin with the two frames considered by Andreoni (1995). Given that our focus is on framing I think it is most instructive to provide a (highly shortened) version of the instructions subjects received. In what Andreoni (1995) called a positive frame, subjects began with 60 tokens in an investment account. They were then asked how many tokens they wanted to invest in an individual exchange and how many to invest in a group exchange. They were told that 'every token you invest in the individual exchange will yield you a return of one.' While, 'every token invested in the group exchange yields a return of $1 / 2$ for each member of the group.' They were also told that there are five members of the group, all, independently, facing the same choice.

These instructions can be mapped into a standard formulation. Let $N=\{1, \ldots, n\}$. denote the set of group members. For any $i \in N$ let $x_{i}$ denote the amount member $i$ allocates to her individual exchange and $g_{i}$ the amount she allocates to the group exchange. The payoff function of subject $i$ can then be written

$$
u_{i}=x_{i}+m \sum_{j \in N} g_{j}
$$

where $m$ is a constant called the marginal per capita return from the public good. If we let $X$ denote the initial number of tokens in the investment account then we have a natural identity

$$
x_{i}+g_{i}=X .
$$


In the Andreoni (1995) experiments the parameters were $n=5, m=0.5$ and $X=60$.

This frame can be characterised on the three dimensions introduced above as follows. (1) Externality: the instructions refer to the positive externality that results from investing in the group exchange. (2) Choice: a subject has to decide how many tokens to invest in both the individual exchange and group exchange. (3) Initial allocation: there are initially zero tokens in both the individual exchange and group exchange. I will refer to this as a positive-both-zero (PBZ) frame. We shall shortly see frames that are different on all three dimensions, with Table 1 serving as a reference for terminology. What I want to emphasize at this point is that the frame used by Andreoni (1995) does not prime the individual or group exchange and so is as neutral as possible.

Consider now, what Andreoni (1995) called the negative frame. As in the PBZ frame, subjects began with 60 tokens in an investment account and were asked how many of these tokens they wanted to invest in an individual exchange and group exchange. Differences come in the way payoffs were explained. Subjects were told that 'every token you invest in the individual exchange will yield you a return of one. ... However, each token you invest in the individual exchange will reduce the earnings of the other players by one half cent each.' They were also told that, 'every token invested in the group exchange yields a return of $1 / 2$ for you. The other members of your group are not affected by your investment in the group exchange.' Finally, subjects were told that they would automatically earn 120 tokens each round. To understand why these automatic 120 tokens are necessary let us check that this frame is strategically equivalent to the PBZ frame. For that we need to substitute $X-x_{i}=g_{i}$ into Eq. (1) to get

$$
u_{i}=x_{i}+m g_{i}+m(n-1) X-m \sum_{j \neq i} x_{j} .
$$

This formulation of the payoff function fits the proceeding instructions, with $m(n-1) X=120$ tokens being earned automatically.

If we compare this frame with the PBZ frame we see that it is exactly the same on the choice and initial allocation dimensions. In both frames the subject has to decide how many tokens to invest in both the individual exchange and group exchange and tokens are initially assigned to the investment account. The frames differ in whether the positive externality from investing in the public good or the negative externality from not investing in the public good are emphasized. Thus, I will refer to this frame

Table 1 Summary of framing terminology

\begin{tabular}{ll}
\hline Dimension & Possibilities \\
\hline Externality & Positive (P) or negative (N) \\
Choice & Give to Both exchanges (B), Give to group exchange (G) or Take from group exchange \\
& $(\mathrm{T})$ \\
$\begin{array}{l}\text { Initial } \\
\text { allocation }\end{array}$ & Zero in both exchanges (Z), in individual exchange (I), or in group exchange (Gp) \\
\hline
\end{tabular}


as a negative-both-zero (NBZ) frame. Comparison of the PBZ and NBZ frame allows us to distinguish a positive-negative framing effect.

It is useful to briefly summarize the evidence for a positive-negative framing effect. Figure 1 plots the average contributions, over ten rounds, observed by Andreoni (1995) and a follow up study by Park (2000). The headline result is easily discernible in that contributions were significantly higher with the PBZ than NBZ frame. Consider next Table 2 which summarizes the details of all linear public good framing studies of which I am aware (and are listed in Gächter et al. 2014). For now, focus solely on the top three studies. These are the only studies that compare frames which vary on the externality dimension and not the give-take or initial allocation dimensions. They all show significantly higher contributions in the PBZ frame. The evidence of a positive-negative framing effect is, therefore, robust and strong. Also worth noting is the study of Nikiforakis (2010) where punishment is shown to be less effective at maintaining cooperation in a linear public good game if subjects receive information on earnings rather than contributions. Given that contribution
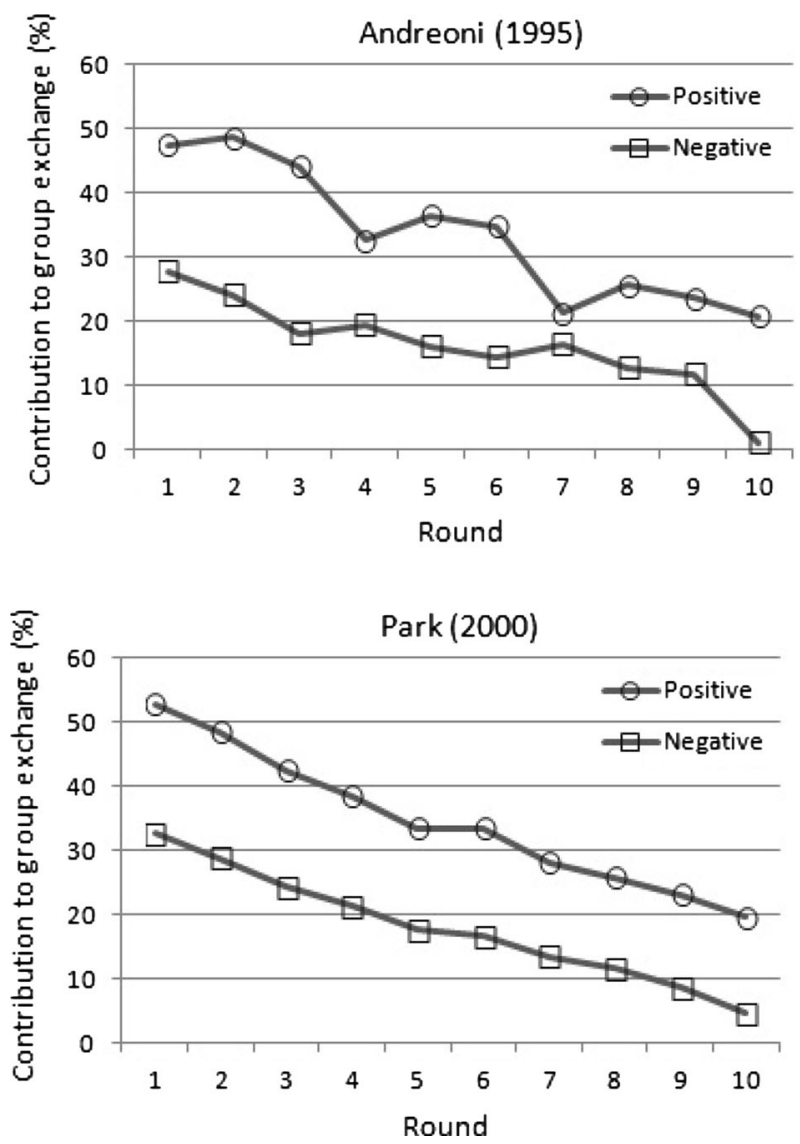

Fig. 1 Average contributions to the group exchange (as a percentage of total possible) in the studies of Andreoni (1995) and Park (2000), distinguishing between a positive (PBZ) and negative (NBZ) frame 
Table 2 A summary of studies looking at framing effects in linear public good games

Study Comparison Difference Comments

\section{Externality dimension}

Fujimoto and Park PBZ and NBZ 22*** (240) Difference driven by men

\begin{tabular}{|c|c|c|c|}
\hline Park (2000) & $\mathrm{PBZ}$ and NBZ & $17 * * *(200)$ & $\begin{array}{l}\text { Repeated game. No difference in proportion of } \\
\text { conditional cooperators }\end{array}$ \\
\hline & & & ated game \\
\hline
\end{tabular}

\section{Choice and initial allocation dimensions}

Fosgaard et al. PGI and PTGp $\quad-2 * * *$ (2042)

Dufwenberg et al. PGI and PTGp (2011)

\begin{tabular}{|c|c|c|c|}
\hline & $\begin{array}{l}\text { Community } \\
\text { label }\end{array}$ & $9(117)$ & \\
\hline $\begin{array}{l}\text { Cubitt et al. } \\
\text { (2011a) }\end{array}$ & PGI and PTGp & 7 (87) & $\begin{array}{l}\text { Little evidence of effect on first order beliefs or } \\
\text { emotions }\end{array}$ \\
\hline \multirow{4}{*}{$\begin{array}{l}\text { Goerg and } \\
\text { Walkowitz } \\
(2010)\end{array}$} & $\begin{array}{l}\text { PGI and PTGp } \\
\text { Helsinki }\end{array}$ & $-10(42)$ & Two player game \\
\hline & Jerusalem & $-2(40)$ & \\
\hline & Abu-Dis & $44 * * *(40)$ & \\
\hline & Chengdu & $29 * * *(40)$ & \\
\hline $\begin{array}{l}\text { Brandts and } \\
\text { Schwieren } \\
(2009)\end{array}$ & PGI and PTGp & $4(100)$ & Make ten independent decisions \\
\hline $\begin{array}{l}\text { Messer et al. } \\
\text { (2007) }\end{array}$ & PGI and PTGp & $-5(70)$ & Repeated game \\
\hline \multirow[t]{2}{*}{ Sell et al. (2002) } & $\begin{array}{l}\text { PGI and PTGp } \\
\text { US }\end{array}$ & $-12 * *(40)$ & Repeated game. Some deception \\
\hline & China & $-14 * *(40)$ & \\
\hline Cookson (2000) & PBZ and PGI & $12 * *(80)$ & Repeated game \\
\hline $\begin{array}{l}\text { Van Dijk and } \\
\text { Wilke (1997) }\end{array}$ & PGI and PTGp & $5(97)$ & Not incentivized \\
\hline $\begin{array}{l}\text { Sell and Son } \\
\text { (1997) }\end{array}$ & PGI and PTGp & $-3(48)$ & Repeated game \\
\hline Fleishman (1988) & $\begin{array}{l}\text { PBZ and } \\
\text { PTGp }\end{array}$ & $1(165)$ & Repeated game. Involved deception \\
\hline \multicolumn{4}{|c|}{ Externality, choice and initial allocation dimensions } \\
\hline Cox (2015) & $\begin{array}{l}\text { PGI and } \\
\text { NTGp }\end{array}$ & $15 * * *(80)$ & Repeated game. Difference driven by men \\
\hline $\begin{array}{l}\text { Khadjavi and } \\
\text { Lange (2015) }\end{array}$ & $\begin{array}{l}\text { PGI and } \\
\text { NTGp }\end{array}$ & $16^{*}(80)$ & Repeated game \\
\hline $\begin{array}{l}\text { Cox and Stoddard } \\
\text { (2015) }\end{array}$ & $\begin{array}{l}\text { PGI and } \\
\text { NTGp }\end{array}$ & $-8(252)$ & $\begin{array}{l}\text { Various treatments varying matching and } \\
\text { feedback }\end{array}$ \\
\hline $\begin{array}{l}\text { Gächter et al. } \\
\text { (2014) }\end{array}$ & $\begin{array}{l}\text { PGI and } \\
\text { NTGp }\end{array}$ & $11 * * *(334)$ & $\begin{array}{l}\text { Strong effect on first order beliefs and proportion } \\
\text { of conditional cooperators }\end{array}$ \\
\hline
\end{tabular}


Table 2 continued

\begin{tabular}{llcl}
\hline Study & Comparison & Difference & Comments \\
\hline Cox et al. (2013) & PGI and & $9(68)$ & \\
& NTGp & & \\
Brandts and & PGI/PTGp and & $-3(144)$ & Make ten independent decisions \\
Schwieren & NBZ & & \\
$(2009)$ & & & \\
\hline
\end{tabular}

The difference is the observed difference in average contributions (as a percentage of the endowment). In studies with repeated games the average is over all periods. The studies are one-shot games unless indicated otherwise. A $* * *, * * *$ indicate significance at the 10,5 and $1 \%$ level (as reported in the original paper, typically Wilcoxon rank-sum test). The number of subjects is given in brackets

feedback emphasizes the positive externality of contributing to the group, while earnings feedback emphasizes the private benefit of not contributing, this result is also consistent with a positive-negative framing effect.

\section{A give-some versus take-some framing effect}

As we have seen, the study of Andreoni (1995) compared frames that differ along the externality dimension but not the choice or initial allocation dimensions. The vast majority of other experimental studies have compared frames that differ along these other two dimensions. There are a large number of possibilities that one could consider and many have been considered (e.g. van Dijk and Wilke 2000). The literature, though, has concentrated for the most part on a, so called, give-some versus take-some distinction and so that is what I will focus on here.

\subsection{Positive-give versus negative-take}

To get us started consider what Khadjavi and Lange (2015) called a GIVE frame. Again, it is instructive to look at the instructions subjects received. Subjects were told that 'At the beginning of each period each participant receives 20 tokens in a private account. You have to decide how many of these 20 tokens you transfer to a group account'. They are then told that their income will consist of any tokens in their private account and 0.4 times the amount of tokens in the group account. For instance, they are told 'your income in tokens in a period hence amounts to $(20-$ your transfer $)+0.4 \times$ (total amount of tokens in the group account).'

Compare this frame with the PBZ frame. The decision subjects have to make is how many tokens they want to transfer to the group account (rather than both the individual and group exchange). Moreover, tokens are initially put in the private account (as opposed to a neutral investment account). This can be captured by writing the payoff function

$$
u_{i}=X-g_{i}+m \sum_{j \in N} g_{j}
$$


where $X$ is the number of tokens initially in the private account. This frame differs from a PBZ frame in both the choice and initial allocation dimensions.

The term give-some, introduced by Dawes (1980), is the standard way to refer this type of frame. This terminology leaves open, however, the crucial question of where the frame sits on the externality dimension. In the spirit of Andreoni (1995), I will say that a frame is positive if the instructions given to subjects focus on actions that will result in a positive externality, such as, transfers to the group account or tokens left in the group account. Conversely, I will say that a frame is negative if the instructions focus on actions that will result in a negative externality, such as, transfers to the private account or tokens withdrawn from the group account. ${ }^{2}$ On this criterion the instructions for Khadjavi and Lange (2015) GIVE frame are positive and so I will use the term positive-give-individual (PGI), where individual recognises that the tokens are initially in the individual or private account. The PGI frame can be recognised as the workhouse of public good experiments.

Consider next what Khadjavi and Lange (2015) call a TAKE frame. Here, subjects are told that there are 80 tokens in the group account and no tokens in their private account. They have to decide how many of the 80 tokens to transfer to their private account. It is simple to see that this frame differs from the PGI frame in the choice and initial allocation dimensions. We can represent this by writing the payoff function

$$
u_{i}=x_{i}+m \sum_{j \in N}\left(X-x_{j}\right)
$$

where $X$ is the number of tokens each subject can withdraw from the group account. Dawes (1980) introduced the term take-some for this type of frame. But, again, the crucial question for us is where the frame sits on the externality dimension. Given that the instructions talk primarily of transfers to the private account the frame can be characterized as negative. The term negative-take-group (NTGp) frame will, therefore, be used, where group recognises that the tokens are initially in the group account.

The studies by Khadjavi and Lange (2015) and Cox (2015) are of particular note because they compare PGI and NTGp frames in a repeated setting comparable to Andreoni (1995). Note that the PGI and NTGp frames differ on all three framing dimensions. Careful account of these differences seems essential and this, I would argue, is what the literature is failing to do. To expand on these points, consider Fig. 2, which plots the average contributions over time observed by Khadjavi and Lange (2015) and Cox (2015) for their PGI and NTGp frames. Both Khadjavi and Lange (2015) and Cox (2015) interpret the results summarized in Fig. 2 as evidence of a give-take framing effect. This interpretation then feeds into the way they analyze data from the more novel treatments considered in their respective studies. But, is there any evidence of a give-take framing effect in Fig. 2? I would argue not. In comparing a positive-give-individual and negative-take-group frame we pick up both a positive-negative and give-take effect. As we have seen, there is strong

\footnotetext{
${ }^{2}$ A characterisation between positive and negative frames inevitably requires subjective judgements given the large variation in instructions used in linear public good game experiments. In the online supplementary material this issue is discussed in more detail with specific reference to the studies listed in Table 2.
} 

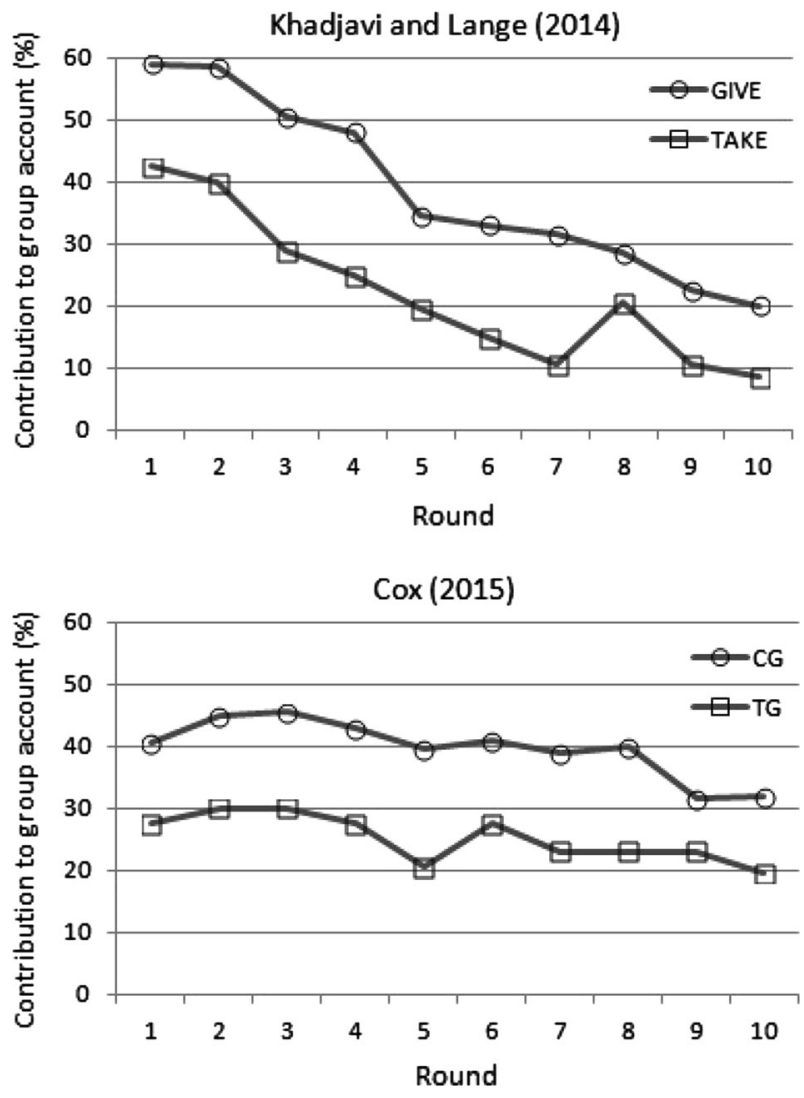

Fig. 2 Average contributions to the group account (as a percentage of total possible) in the studies of Khadjavi and Lange (2015) and Cox (2015), distinguishing between a PGI (GIVE and CG) and NTGp (TAKE and TG) frame

evidence of a positive-negative framing effect. As a first approximation this could be 'subtracted' to uncover the give-take framing effect. Yet, Fig. 2 looks remarkably similar to Fig. $1 .^{3}$ So, while a give-take framing effect may exist, Fig. 2 cannot be taken as evidence of its existence. The differences we observe between the PGI and NTGp frames may simply be due to the positive-negative framing effect.

\subsection{Positive-give versus negative-give}

To get convincing evidence of a give-take framing effect we ideally want to eliminate any difference on the externality dimension. Fortunately, several studies

\footnotetext{
3 Cookson (2000) compares a PGI and PBZ frame. He found higher contributions in a PGI than PBZ frame (an average of 50 versus $33 \%$ ). He also found that contributions declined less in the PGI frame. Unfortunately, we do not have any evidence on the comparison between an NTGp and NBZ frame. So, we can do no more than speculate. But, any differences there are between Figs. 1 and 2 are not inconsistent with the findings of Cookson (2000).
} 


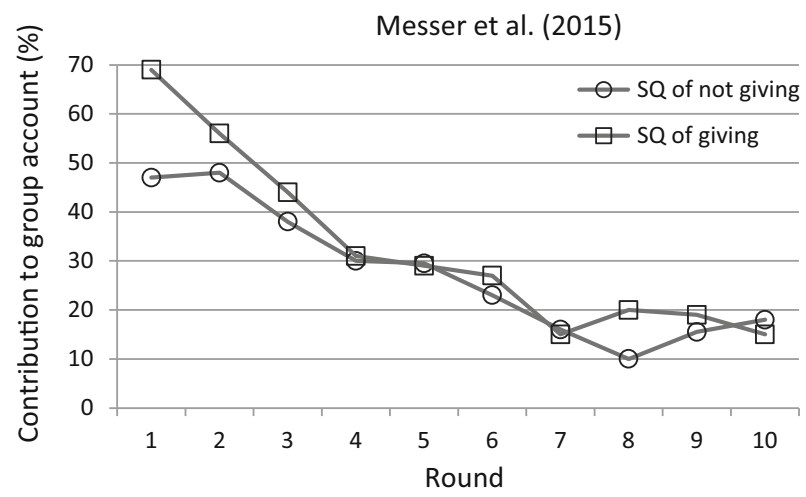

Fig. 3 Average contributions to the group account (as a percentage of total possible) in the study of Messer et al. (2007), distinguishing between a PGI (status quo of not giving) and PTGp (status quo of giving) frame

do this by comparing PGI and positive-take-group (PTGp) frames. Consider, for instance, the Take- $\mathrm{N}$ frame of Cubitt et al. (2011a) where the instructions contain statements like 'if you withdraw one token less from the project, the income from the project received by the whole group together increases by 1.5 Guilders.' Note how this formulation looks at the positive externality of not taking from the group account. Studies that compare PGI and PTGp frames allow crucial insight on whether there is a give-take framing effect.

For completeness, I will look first at the study of Messer et al. (2007). This is the only study we have not yet considered that treats a repeated setting directly comparable to Andreoni (1995). Crucially, for our purposes, it compares a PGI and PTGp frame and so there is no difference on the externality dimension. Figure 3 plots average contributions and can be directly compared to Figs. 1 and 2. The contrast between Figs. 1, 2 and 3 is clear enough and consistent with my claim that the differences observed in Fig. 2 are due to a positive-negative framing effect and not a give-take framing effect.

Let us now return to Table 2. The bottom half of Table 2 looks at studies with treatments that vary also on the externality dimension. With the exception of Brandts and Schwieren (2009), Cox et al. (2013) and Cox (2015) all studies show a strong effect. The lack of an effect in Cox et al. (2013) could be put down to a relatively small sample size. The results of Brandts and Schwieren (2009) and Cox (2015) are less easy to reconcile and provide something of a puzzle. Both Brandts and Schwieren (2009) and Cox (2015) investigate this puzzle and find that behaviour is significantly more 'extreme' when there is a negative frame, with more subjects contributing zero or the maximum, but that this does not affect the average.

The middle part of Table 2 looks at studies with treatments that do not vary on the externality dimension. Here, few studies show a strong effect in average contributions. Moreover, the studies are split down the middle in terms of an upward or downward give-take effect. Cookson (2000) provides arguably the strongest evidence but note that this is a comparison between a both and give frame (not give and take). Goerg and Walkowitz (2010) find strong evidence of cross-cultural 
differences but the results from Helsinki and Jerusalem are consistent with the lack of a give-take framing effect with 'standard' subject pools. The stark contrast between the top and middle of Table 2 makes clear that the distinction between the externality, choice and initial allocation dimensions is an important one.

\section{Concluding discussion}

My objective in this comment was to argue that a more careful interpretation of framing effects in linear public good games is necessary. Once we take into account the distinction between a positive-negative externality and give-take choice distinction it becomes easier to make sense of existing results on framing effects. Specifically, there is: (a) strong evidence of a positive-negative framing effect, but (b) little evidence of a give-take framing effect on average contributions. The results in the literature need not, therefore, be as inconsistent as is often claimed. Existing interpretations of framing results may, however, still need re-evaluating. To give one example: the motivation Cubitt et al. (2011a) give for their study is to test whether evidence on social preferences (particularly in terms of punishment in public good games) is robust to framing effects. They understandably conclude (p. 257) that 'the social preferences we observe are robust to our framing manipulation.' But, was the 'barrier for a pass' set too low? A tougher test would be whether social preferences are robust to a positive-negative framing effect. The results of Nikiforakis (2010) suggest that they might not be.

To finish, I should highlight that give-take framing has been shown to influence attitudes, beliefs, moral judgements, the proportion of free-riders and misperceptions, even if the net effect on average contributions was small (e.g. Brandts and Schwieren 2009; Cubitt et al. 2011a, b; Dufwenberg et al. 2011; Fosgaard et al. 2014, 2015). The absence of a give-take effect on average contributions does not, therefore, mean the absence of a give-take effect. Similarly, there is evidence that variation on the initial allocation dimension can influence the proportion of freeriders (e.g. Khadjavi and Lange 2015). There is also evidence to suggest that the positive-negative framing effect is diminished in a setting where the public account is initially in deficit (Cox 2015, see also De Heus et al. 2010). Moreover, the results of Cox and Stoddard (2015) highlight the need for a better understanding of the negative-positive framing effect. Clearly, many open questions remain for further study. I hope to have convinced in this paper that a recognition of the distinction between positive-negative and give-take framing effects is important in answering those questions.

Acknowledgments I would like to thank the editor, Nikos Nikiforakis, and three anonymous referees for their constructive comments and suggestions on earlier versions of the paper.

\section{References}

Andreoni, J. (1995). Warm-glow versus cold-prickle: the effects of positive and negative framing on cooperation in experiments. The Quarterly Journal of Economics, 110(1), 1-21. 
Brandts, J., \& Schwieren, C. (2009). Frames and economic behavior. (Working paper Universitat Autonoma de Barcelona)

Cookson, R. (2000). Framing effects in public goods experiments. Experimental Economics, 3(1), 55-79.

Cox, C. A. (2015). Decomposing the effects of negative framing in linear public goods games. Economics Letters, 126, 63-65.

Cox, J. C., Ostrom, E., Sadiraj, V., \& Walker, J. M. (2013). Provision versus appropriation in symmetric and asymmetric social dilemmas. Southern Economic Journal, 79(3), 496-512.

Cox, C. A., \& Stoddard, B. (2015). Framing and feedback in social dilemmas with partners and strangers. Games, 6(4), 394-412.

Cubitt, R. P., Drouvelis, M., \& Gächter, S. (2011a). Framing and free riding: emotional responses and punishment in social dilemma games. Experimental Economics, 14(2), 254-272.

Cubitt, R. P., Drouvelis, M., Gächter, S., \& Kabalin, R. (2011b). Moral judgments in social dilemmas: how bad is free riding? Journal of Public Economics, 95(3), 253-264.

Dawes, R. M. (1980). Social dilemmas. Annual Review of Psychology, 31(1), 169-193.

De Heus, P., Hoogervorst, N., \& Van Dijk, E. (2010). Framing prisoners and chickens: valence effects in the prisoner's dilemma and the chicken game. Journal of Experimental Social Psychology, 46(5), 736-742.

Dufwenberg, M., Gächter, S., \& Hennig-Schmidt, H. (2011). The framing of games and the psychology of play. Games and Economic Behavior, 73(2), 459-478.

Ellingsen, T., Johannesson, M., Mollerstrom, J., \& Munkhammar, S. (2012). Social framing effects: preferences or beliefs? Games and Economic Behavior, 76(1), 117-130.

Fleishman, J. A. (1988). The effects of decision framing and others' behavior on cooperation in a social dilemma. Journal of Conflict Resolution, 32(1), 162-180.

Fosgaard, T. R., Hansen, L. G., \& Wengström, E. (2014). Understanding the nature of cooperation variability. Journal of Public Economics, 120, 134-143.

Fosgaard, T., Hansen, L. G., \& Wengström, E. (2015). Framing and misperceptions in a public good experiment. Scandinavian Journal of Economics, forthcoming.

Fujimoto, H., \& Park, E. S. (2010). Framing effects and gender differences in voluntary public goods provision experiments. The Journal of Socio-Economics, 39(4), 455-457.

Gächter, S., Kölle, F., \& Quercia, S. (2014) The ABC of cooperation in voluntary contribution and common pool extraction games. (Working paper, University of Nottingham)

Goerg, S. J., \& Walkowitz, G. (2010). On the prevalence of framing effects across subject-pools in a twoperson cooperation game. Journal of Economic Psychology, 31(6), 849-859.

Khadjavi, M., \& Lange, A. (2015). Doing good or doing harm: experimental evidence on giving and taking in public good games. Experimental Economics, 18, 432-441.

Messer, K. D., Zarghamee, H., Kaiser, H. M., \& Schulze, W. D. (2007). New hope for the voluntary contributions mechanism: the effects of context. Journal of Public Economics, 91(9), 1783-1799.

Nikiforakis, N. (2010). Feedback, punishment and cooperation in public good experiments. Games and Economic Behavior, 68(2), 689-702.

Park, E. S. (2000). Warm-glow versus cold-prickle: a further experimental study of framing effects on free-riding. Journal of Economic Behavior \& Organization, 43(4), 405-421.

Sell, J., Chen, Z. Y., Hunter-Holmes, P., \& Johansson, A. C. (2002). A cross-cultural comparison of public good and resource good settings. Social Psychology Quarterly, 65(3), 285-297

Sell, J., \& Son, Y. (1997). Comparing public goods with common pool resources: Three experiments. Social Psychology Quarterly, 60(2), 118-137.

van Dijk, E., \& Wilke, H. (1997). Is it mine or is it ours? Framing property rights and decision making in social dilemmas. Organizational Behavior and Human Decision Processes, 71(2), 195-209.

Van Dijk, E., \& Wilke, H. (2000). Decision-induced focusing in social dilemmas: give-some, keep-some, take-some, and leave-some dilemmas. Journal of Personality and Social Psychology, 78(1), 92. 